\title{
Electron/transport in (Mo/Au)/AlGaN/GaN Schottky diode
}

\author{
Fikria Jabli $^{\mathrm{a}}$, Hana Mosbahi ${ }^{\mathrm{a}}$, Malek Gassoumi ${ }^{\mathrm{a}, \mathrm{d} *}$, Christophe Gaquiere ${ }^{\mathrm{c}}$, \\ Mohamed Ali Zaidi ${ }^{\mathrm{a}, \mathrm{b}}$, Hassen Maaref ${ }^{\mathrm{a}}$ \\ ${ }^{a}$ Laboratoire de Micro-Optoélectroniques et Nanostructures, Faculté des Sciences de Monastir, Université de \\ Monastir, Monastir 5000. \\ ${ }^{b}$ Arabie saoudite - Zolfi 11932 - College of Science en Zolfi - BP: 1712 \\ 'Institut d'Electronique de Microélectronique et de Nanotechnologie IEMN, Département hyperfréquences et \\ Semiconducteurs, Université des Sciences et Technologies de Lille, Avenue Poincaré, 59652 Villeneuve d'Ascq \\ Cedex, France \\ ${ }^{d}$ Department of Physics, College of Science, Qassim University, Buraidah 51452, Saudi Arabia
}

\section{Corresponding authors: gassoumimalek@yahoo.fr}

\begin{abstract}
The knowledge of the conduction mechanisms in a Schottky barrier is essential to calculate the Schottky barrier parameters and to explain the observed effects. In the present work, we report temperaturedependent current-voltage characteristics of $(\mathrm{Mo} / \mathrm{Au}) / \mathrm{Al}_{0.26} \mathrm{Ga}_{0.74} \mathrm{~N} / \mathrm{GaN} / \mathrm{Si} / \mathrm{Schottky}$ barrier diodes. Measurements were performed in the temperature range of $80-300$ K.Results have been explained based on the thermionic emission mechanism with lateral inhomogeneity at the (Mo/Au/AlGaN/GaN/Si) interface. As is shown, the barrier height $\Phi_{B 0}$ as well as the ideality factor $n$ exhibit an important temperature dependence and the anomaly resulting from this dependence has been explained by invoking two sets of Gaussian distributions at the metal/semiconductor interface for temperature ranging from $80 \mathrm{~K}$ to $160 \mathrm{~K}$ and from $160 \mathrm{~K}$ to $300 \mathrm{~K}$, respectively. It is also found that the values of $R_{s}$ obtained from Cheung's method strongly depend on temperature and decrease with decreasing temperature.
\end{abstract}

Keywords: Schottky barrier, Current-voltage characteristics, Ideality factor, Inhomogeneity, Thermionic emission.

\section{Introduction}

AlGaN/GaN High Electron Mobility Transistors (HEMTs) have attracted a great deal of attention because of their potential in high-power and high-frequency applications. The main advantages of the $\mathrm{AlGaN} / \mathrm{GaN}$ system are the high breakdown voltage due to large critical electric field, the wide band gap and the high saturation electron drift velocity [1].The performance and reliability of these devices can be improved by using high quality Schottky and ohmic contacts. Analysis of current-voltage measurements versus temperature, gives detailed information on the electron transport and allows to extract the main parameters such as: the series resistance $\mathrm{R}_{\mathrm{s}}$, the ideality factor $\mathrm{n}$, and the barrier height $\Phi_{\mathrm{B} 0}$. In this paper, we have used the forward bias I-V measurements as a function of temperature in the range of $80-300 \mathrm{~K}$ to evaluate the series resistance, the ideality factor and the barrier height characterizing the device's electrical behavior. Generally in the metal/semiconductor contacts, the ideal situation is never achieved because the BH is often influenced by interfacial contaminants, or/and inhomogeneities .It was observed that these contaminants at a MS interface may also introduce an inhomogeneity through the generation of defects $[2,3]$.

\subsection{Experimental}

\section{Results And Discussion}

The AlGaN/GaN HEMTs under investigation are grown on silicon (111) substrate by using molecular beam epitaxy (MBE). The active layers consist in a $500 \mathrm{~nm}$ thick of undoped AlN/AlGaN buffer, a $1.8 \mu \mathrm{m}$ undoped $\mathrm{GaN}$ channel, a $23 \mathrm{~nm}$ thick of undoped $\mathrm{Al}_{0.26} \mathrm{Ga}_{0.74} \mathrm{~N}$ barrier and a $1 \mathrm{~nm} \mathrm{n+-GaN}$ cap layer. The device processing is made following conventional HEMT fabrication steps. The ohmic contact pads are patterned using e-beam lithography. Hereafter, the metallization by means of evaporated $12 / 200 / 40 / 100 \mathrm{~nm} \mathrm{Ti} / \mathrm{Al} / \mathrm{Ni} / \mathrm{Au}$ is deposited at $900^{\circ} \mathrm{C}$ during 30s. The Schottky gate is realized using $100 / 150 \mathrm{~nm} \mathrm{Mo} / \mathrm{Au}$ layers. On the other hand, the $\mathrm{AlGaN} / \mathrm{GaN}$ HEMTs are passivated by $100 / 50 \mathrm{~nm} \mathrm{SiO} / 2 / \mathrm{SiN}_{\text {with }} \mathrm{NH}_{3}$ and $\mathrm{N}_{2} \mathrm{O}$ pretreatments.

\subsection{Discussion}

Fig.2 shows experimental forward and reverse bias characteristics in semi-logarithm scale of Schottky barrier diode. Measurements have been carried out in the temperature range 80-300 K. It is seen that the current increases with temperature and deviates noticeably from linear trend. This behavior is due mainly to the 
strong dependence of both barrier height and ideality factor on temperature and partly from the nonlinearity of the Richardson plots $[4,5]$. As is also found, the (I-V) characteristics exhibit a crossing at high forward bias voltages and more precisely near $\mathrm{V}_{\text {bias }}=5.14 \mathrm{~V}$. According to that reported in Ref. [6], the series resistance $\mathrm{R}_{\mathrm{s}}$ could be at the origin of this crossing.

\section{A. Electrical Parameters}

Firstly, our purpose will be attempted to evaluate the parameters Rs, $\mathrm{I}_{0}$ and $\Phi_{\mathrm{B}_{0}}$ from the relevant I-V characteristics.

When $R_{s}=0$, The (I-V-T) characteristics of a Schottky diode detector can be described according to the thermionic emission theory.

The current from the forward (I-V-T) plot is obtained using the relation [7]:

$\mathrm{I}=\mathrm{I}_{0} \exp \left(\frac{\mathrm{qV}}{\mathrm{\eta} \mathrm{KT}}\right)\left[1-\exp \left(\frac{-\mathrm{qV}}{\mathrm{KT}}\right)\right]$

where $\boldsymbol{\eta}$ is the ideality factor, $\mathrm{V}$ is the applied bias voltage, $\mathrm{K}$ is the Boltzman constant, $\mathrm{q}$ is the electron charge, $\mathrm{T}$ is the absolute temperature and $\mathrm{I}_{0}$ is the saturated current.

For bias voltageV $>\frac{3 \mathrm{KT}}{\mathrm{q}}$, Eq. (1) can be rewritten as :

$I=I_{0} \exp \left(\frac{q V}{\mathrm{n}_{\mathrm{KT}} \mathrm{T}}\right)(2)$

with :

$I_{0}=S A^{*} T^{2} \exp \left(-\frac{q \Phi_{B 0}}{K T}\right)$

Here, $S$ represents the effective contact area, $A^{*}$ is the Richardson constant $\left(\mathrm{A}^{*}=26,4 \mathrm{~A} / \mathrm{cm}^{2} \mathrm{~K}^{2}\right.$ for $\mathrm{GaN})$ and $\Phi_{\mathrm{B} 0}$ is the barrier height at zero bias.

At relatively high temperatures, the thermionic emission is predominant and governs the current conduction. As temperature decreases, the barrier heightis lowered due to the increase in electron thermal energy [8].At a given temperature, the linear portion of the $\mathrm{Ln} I$ versus $\mathrm{V}$ is used to determine the saturation current $\mathrm{I}_{0}$ by extrapolation to zero-bias. For the ideality factor, it can be evaluated from the slope of the Ln I-V plots by using the relation:

$\eta=\frac{q}{K T} \frac{d V}{d \operatorname{Ln}(1)}$

The ideality factor accounts for the deviation of a real diode with respect to the predictions of the thermionic emission theory. In otherwise, the ideality factor is introduced to explain the discrepancy of experimental I-V data from the ideal thermionic model and to include the contribution of other current transport mechanisms.

The large value of $\boldsymbol{\eta}$ at low temperature is attributed to the presence of interface states and barrier inhomogeneity at $\mathrm{M} / \mathrm{S}$ interface [9-11]. From the relevant values of $\boldsymbol{\eta}$, we can conclude, if they are greater than one, that the thermionic emission does not only exist but there are other mechanisms that contribute to the current conduction such as the tunneling mechanism assisted by traps at the metal/semiconductor interface. The temperature dependence of the barrier height and ideality factor in a Schottky junction is called the " $\mathrm{T}_{0}$ effect" [11-14]. Such dependence is usually observed in Schottky barrier diodes. In Fig.3,we report the Schottky barrier height as well as the ideality factor versus temperature. It is seen that the plots show a linear dependence with reversed tendencies. As an attempt of explanation, the increasing of $\Phi_{\mathrm{B} 0}$ and the decrease in ideality factor $\eta$ at low temperature are possibly caused by inhomogeneities in thicknesses and alloy compositions of the epilayers, a non-uniformity of the interfacial charges, the presence of a thin insulating layer between the metal and the semiconductor material or the surface states $[15,16]$. It is worth to notice that these imperfections can introduce inhomogeneities into the transport current $[3,17-20]$. Therefore, the transport of current across the metalsemiconductor heterointerface is a temperature-activated process. This can explain very well why the electron transport at low temperature is dominated by the current through the patches of low barrier heights.

In a model developed by Tung [12], small regions, so-called "patches" with lower barrier heights than the junction's main barrier are assumed to exist at the junction. The area of these patches might be much smaller than the total area of the diode through which charge carriers can flow. Furthermore, Anilturk et Turan have suggested that the current flowing through patches may also be considered as a tunneling current $[21,22]$.

The homogeneous barrier height is essential for the $\mathrm{AlGaN} / \mathrm{GaN}$ SBD and needs to be extracted. A linear trend is obtained between experimental Schottky barrier heights and the ideality factor, as illustrated in Fig.4. The relevant value of $\Phi_{\mathrm{B} 0}$ for $\boldsymbol{\eta}=1$ is in order of $0.45 \mathrm{eV}$, which corresponds to the barrier height of an homogeneous Schoottky contact. 
From the reverse bias $\mathrm{I}-\mathrm{V}$ at $(-10 \mathrm{~V})$, it has been observed that the leakage current increases with temperature up to $300 \mathrm{~K}$, see Fig.5. This increase in leakage current in AlGaN/GaN HEMTs is due presumably to the surface-related traps and temperature-assisted tunneling mechanism.

For $\mathrm{R}_{\mathrm{s}} \neq 0$, Eq. 1 , can be rewritten as:

$\mathrm{I}=\mathrm{I}_{0} \exp \left(\frac{\mathrm{q}\left(\mathrm{V}-\mathrm{I} \mathrm{R}_{\mathrm{g}}\right)}{\mathrm{n} \mathrm{KT}}\right)$

In which, $\mathrm{R}_{\mathrm{S}}$ is the series resistance and $\mathrm{I}$ is the thermionic current passing through the Schottky contact barrier. The series resistance can be evaluated from the forward bias current-voltage data using the method developed by Cheung [23]. It is given according to:

$\frac{\mathrm{dV}}{\mathrm{d}(\mathrm{LnI})}=\mathrm{I} \mathrm{R} \mathrm{R}_{\mathrm{s}}+\mathrm{\eta}\left(\frac{\mathrm{KT}}{\mathrm{q}}\right)$

As shown, $R_{s}$ is the slope of the $d V / d L n I$ versus I plot at a fixed temperature. Whereas $\eta \mathrm{kt} / \mathrm{q}$ corresponds to the $y$-intercept. It has been found that the series resistance increases with temperature (see Fig.6). It is also observed that at low current, the increase in series resistance is morelarge than that at high current. It is worth to mention that the variation of $\mathrm{R}_{\mathrm{S}}$ with temperature may be due to the factors responsible for the increase in ideality factor $\boldsymbol{\eta}$ and the lack of free carriers [24]. According to Tekeli et al. [25,26], the variation of $R_{s}$ with temperature is expected to be occurring in semiconductors the temperature range where there is no freezing of carriers[27].

Another approach has been proposed by Cheung et al [28], it can allow to evaluate the Schottky barrier height. The use of this model is based on the following set of equations:

$\mathrm{H}(\mathrm{I})=\mathrm{V}-\mathrm{\eta} \frac{\mathrm{KT}}{\mathrm{q}} \operatorname{Ln}\left(\frac{\mathrm{I}}{\mathrm{SA}^{*} \mathrm{~T}^{2}}\right)$

and

$\mathrm{H}(\mathrm{I})=\mathrm{IR}_{\mathrm{s}}+\eta \Phi_{\mathrm{BO}}$

All of the parameters were defined above. Then, it will be possible to determine $\Phi_{\mathrm{B} 0}$ provided that values of $\boldsymbol{\eta}$ have to be taken from Eq. (5). Results are reported in Fig.7.

On the other hand, the Werner's model is the most commonly used to investigate the Gaussian distribution of barrier heights which varies around a mean value $\Phi_{\mathrm{B} 0}[29,30]$.It should be noted that such a lateral distribution could be the main cause of the abnormal deviations of current-voltage characteristics of a Schottky diode from the thermionic emission mechanism. According to this Gaussian distribution, the expression of the barrier height is given by:

$\Phi_{\mathrm{BO}}=\overline{\Phi_{\mathrm{BO}}}-\frac{\mathrm{q} \sigma_{0}^{2}}{2 \mathrm{KT}}$

Where $\Phi_{\mathrm{B} 0}$ is the apparent Schottky barrier height measured from the forward bias I-V characteristics and $\sigma_{0}$ representsthe zero bias standard deviation of the Schottky barrier height distribution.

According to Eq. (7), the plot of $\Phi_{\mathrm{B} 0}$ versus $1 / 2 \mathrm{kTshould}$ be a straight line with $\mathrm{y}$-axis intercept corresponding to the mean barrier height $\Phi_{\mathrm{B} 0}$ and the slope gives the standard deviation $\sigma_{0}$. The temperature dependence of $\sigma_{0}$ is usually small and can be neglected. The standard deviation is a measure of the barrier homogeneity, the lower value of $\sigma_{0}$ corresponds to more homogeneous barrier heights. From Eq. (7), we can also see that the apparent SBH is always lower than the mean value of the barrier distribution. The plot of $\Phi_{\mathrm{B} 0}$ versus 1/2KT exhibits two straight lines, as shown in Fig.8. Such a trend is already observed in studyingthe barrier height as well as the ideality factor. So we have obtained two sets of values for $\overline{\Phi_{\mathrm{B} 0}}$ and $\sigma_{0}$ in the temperature ranges $160-300 \mathrm{~K}$ and $80-160 \mathrm{~K}$ : in the first region are $\overline{\Phi_{\mathrm{B} 01}}=0.672 \mathrm{eV}$ and $\sigma_{01}=117 \mathrm{mV}$, and in the second region $\overline{\Phi_{\mathrm{BO} 2}}=0.273 \mathrm{eV}$ and $\sigma_{02}=48.9 \mathrm{mV}$. This two-phases behavior of the Schottky barrier has been observed for diodes based on GaN, InPand Si [31-35] as well.Yu-Long et al.have attributed this double Gaussian distribution of the barrier height to deep lying defects located at the heterointerface.

For the ideality factor $\boldsymbol{\eta}$, and based on the Gaussian distribution model, an inverse proportionality as a function of temperature can be shown by using the expression [19]:

$$
\frac{1}{\eta_{\mathrm{ap}}}=1-\rho_{2}-\frac{\mathrm{q} \rho_{\mathrm{s}}}{2 \mathrm{KT}}
$$

Here $\eta_{\mathrm{ap}}$ is the apparent ideality factor as deduced from experimental data, $\rho_{2}$ is the voltage coefficient of the mean $\mathrm{SBH}$, and $\rho_{3}$ is the voltage coefficient of the standard deviation. Similarly, as can be clearly seen from Fig.9, the plot of $1 / \eta_{\text {ap }}$ versus $\mathrm{q} / 2 \mathrm{kT}$ presents different characteristics in the two temperature ranges because the diode contains two barrier height distributions. The linear behavior of this plot demonstrates that the $\eta$ is related to the voltage deformation of the SBH. 
The values obtained for $\rho_{2}$ and $\rho_{3}$ from the $y$-axis intercept and the slope of the straight lines are respectively: $0.139 \mathrm{Vand} 0.018 \mathrm{~V}$ in temperature range $160-300 \mathrm{~K}$ and $0.671 \mathrm{~V}$ and $0.0023 \mathrm{~V}$ for temperature ranging from 80 to $160 \mathrm{~K}$. The lower value of $\rho_{3}$ in the second temperature range indicates that the distribution of the SBH becomes more homogenous as the bias voltage increases. The extracted values of the mean barrier height and the standard deviation clearly indicate the presence of interface inhomogeneities and potential fluctuations at the interface.

To explain these discrepancies according to the Gaussian distribution of the barrier height, we can rewrite Eq. (1) under the form:

$\operatorname{Ln}\left(\frac{\mathrm{I}_{0}}{\mathrm{~T}^{2}}\right)-\frac{\mathrm{q}^{2} \sigma_{0}^{2}}{\left(2 \mathrm{~K}^{2} \mathrm{~T}^{2}\right)}=\operatorname{Ln}\left(\mathrm{AA}^{*}\right)-\left(\frac{\mathrm{q} \overline{\mathrm{\Phi}_{0}}}{\mathrm{KT}}\right)$

Fig.10 depicts the Richardson plot of $\left[\operatorname{Ln} \frac{I_{0}}{T^{2}}-\frac{q^{2} \sigma_{0}^{2}}{2 K^{2} T^{2}}\right]$ versus $\frac{1}{K T}$. As can be seen, the plot shows two lines in thetemperature range studied. The mean barrier height $\Phi_{\mathrm{B} 0}$ and the Richardson constant $\mathrm{A}^{*}$ were obtained respectively from the slope and the y-axis intercept of these straight lines. The relevant values are $0.679 \mathrm{eV}$ and $51.32 \mathrm{~A} / \mathrm{cm}^{2} \mathrm{~K}^{2}$ in the temperature $160-300 \mathrm{~K}$ and $0.269 \mathrm{eV}$ and $29.76 \mathrm{~A} / \mathrm{cm}^{2} \mathrm{~K}^{2}$ as temperature varies between 80 and $120 \mathrm{~K}$. It has to be noticed that the values of the Richardson coefficient are close to the theoretical value $26.4 \mathrm{~A} / \mathrm{cm}^{2} \mathrm{~K}^{2}$. Zhou et al. have also found that the value of $\mathrm{A}^{*}$ as determined by a modified Richardson's plot in GaN-related SBD is close to the theoretical [19]. The nearness of both calculated and measured Richardson constant proves the success of the Gaussian distribution model explaining the temperature dependence of I-V characteristics obtained for $\mathrm{Mo} / \mathrm{Au}$ Schottky diodes.

Furthermore, the decomposition on two straight lines implies that at least two different currentmechanisms are present and govern the electron transport. Each one of them corresponds to a Gaussian distribution of SBs. However, it is obvious that the current at high temperature results from the thermionic emission.

\section{Summary And Conclusions}

In the present work, we have reported temperature-dependent (I-V) characteristics of a $(\mathrm{Mo} / \mathrm{Au}) / \mathrm{AlGaN} / \mathrm{GaN} / \mathrm{Si}$ Schottky diode in the temperature range $80-300 \mathrm{~K}$. Obtained parameters such as barrier height, ideality factor and series resistance from forward I-V characteristics show a strong dependence on temperature. The increase in ideality factor and the decreasing trend of the barrier height have been explained based on the thermionic emission with the assumption of Gaussian distribution of the barrier heights at the interface. As has also been found, the thermionic emission model is not able alone to explain well the Schottky barrier heights thus extracted from the (I-V) characteristics. To overcome this, we have adopted more elaboration models. It was revealed that these are interface inhomogeneities and potentiel fluctuations to account for. In addition, the nonlinearity in Richardson plots gives further evidence of the existence of inhomogeneous Schottky barrier heights.

\section{References}

[1]. H. Mosbahi, M. Gassoumi, I.Saidi, H.Mejri, C. Gaquière, M.A. Zaidi,H. Maaref. Current Applied Physics. 13, (2013) 1359.

[2]. F. Iucolano, F. Roccaforte, F. Giannazzo, V. Raineri, J. Appl. Phys. 104 (2008).

[3]. S. Arulkumaran, T. Egawa, H. Ishikawa, M. Umeno, T. Jimbo, IEEETrans. Electron Devices 48 (2001) 573 e580.

[4]. I. Dokmee, S. Altindal, Semicond. Sci. Technol. 21 (2006) 1053.

[5]. A. Gumus, A. Trust, N. Yalcin, J. Appl. Phys. 91 (2002) 245.

[6]. P. Chattopadhyay, D.P. Haldar, Appl. Surf. Sci. 143 (1999) 287.

[7]. S.M. Sze, Physics of Semiconductor Devices, second ed., Willey, New York, 1981.

[8]. A.R. Hefner, R. Singh, J. Lai, D.W. Berning, S. Bouche, C. Chapuy, IEEE Trans. Power Electron. 16 (2001) 273.

[9]. S. Zeyrek, S_. Altındal, H. Yuzer, M.M. Bulbul, Appl. Surf. Sci. 252 (2006) 2999.

[10]. S.M. Sze, Physics of Semiconductor Devices, second ed., Willey, New York,1981.

[11]. E.H. Rhoderick, R.H. Williams, Metal Semiconductor Contacts, second ed., Clarendon Press, Oxford, 1988.

[12]. R. T. Tung, Phys. Rev. B, 45, (1992), 13509.

[13]. T. G"oksu, N. Yıldırım, H. Korkut, A. F. “Ozdemir, A. Turut and A. K”ok, ce, Microelectron. Engineer., 87, (2010),1781.

[14]. H. Korkut, N. Yıldırım and A. Turut, Microelectron. Engineer., 86, (2009), 111.

[15]. S. Zhu, R.L. Meirhaeghe, S. Forment, G.P. Ru, X.P. Qu, B.Z. Li, Solid-State Electron. 48 (2004)1205.

[16]. S. Karatas, S. Altindal, A. Turut, A. Ozmen, Appl. Surf. Sci. 217 (2003)250.

[17]. J.H. Werner, H.H. Guttler, Barrier inhomogeneities at Schottky contacts, J. Appl. Phys. 69 (1991) $1522 \mathrm{e} 1533$.

[18]. E.V. Kalinina, N.I. Kuznetsov, V.A. Dmitriev, K.G. Irvine, C.H. Carter, J. Electron. Mater. 25 (1996) 831 e834.

[19]. Y. Zhou, D. Wang, C. Ahyi, C.C. Tin, J. Williams, M. Park, N.M. Williams,Hanser, E.A. Preble, J. Appl. Phys. 101 (2007).

[20]. N. Yildirim, K. Ejderha, A. Turut, On temperature-dependent experimental IeV and CeV data of Ni/n-GaNSchottky contacts, J. Appl. Phys

[21]. O. S. Anilturk and R. Turan, Semicond. Sci. Technol., 14, (1999), 1060.

[22]. O. S. Anilturk and R. Turan, Solid-State Electron., 44, (2000), 41.

[23]. K. Cheung, N.W. Cheung, Appl. Phys. Lett. 49 (1986) 85.

[24]. S. Chand, J. Kumar, J. Appl. Phys. 80 (1996) 288.

[25]. Z. Tekeli, S_. Altindal, M. Cakmak, S_. O” zc, elik, D. Caliskan, and E. O” zbay,J. Appl. Phys. 102, 054510 (2007). 
[26]. Z. Tekeli, S_. Altindal, M. Cakmak, S. O“ zc, elik, and E. O“ zbay, Microelectronic Eng. 85, 2316 (2008).

[27]. Salah Saadaoui, Mohamed Mongi Ben Salem, Malek Gassoumi, HassenMaaref, and Christophe Gaquière. J. Appl.Phys.110,013701(2011).

[28]. O. Demircioglu , S_. Karatas , N. Yıldırım , O.F. Bakkaloglu . Microelectronic Engineering 88 (2011) $2997-3002$.

[29]. J. Osvald, Zs.J. Horvath, Appl. Surf. Sci. 234 (2004) 349.

[30]. S. Chand, S. Bala, Appl. Surf. Sci. 252 (2005) 358.

[31]. Y.-L. Jiang, G.-P. Ru, F. Lu, X.-P. Qu, B.-Z. Li, and S. Yang, Journal of AppliedPhysics, vol. 93, no. 2, pp. 866-870, (2003).

[32]. G. M. Vanalme, L. Goubert, R. L. V. Meirhaeghe, F. Cardon, and P. V. Daele, Semiconductor Science and Technology, vol. 14, no. 9, p. 871, (1999).

[33]. S. Demirezen and S. AltIndal, Current Applied Physics, vol. 10, no. 4, pp. 1188 - 1195, (2010).

[34]. M. Mamor, Journal of Physics: Condensed Matter, vol. 21, no. 33, p. 335802,(2009).

[35]. S. Huang and F. Lu, Applied Surface Science, vol. 252, no. 12, pp. 4027 - 4032, (2006)

\section{Figures Captions}

Fig.1 Experimental forward and reverse current-voltage characteristics of the $(\mathrm{Mo} / \mathrm{Au}) / \mathrm{Al}_{0.26} \mathrm{Ga}_{0.74} \mathrm{~N} / \mathrm{GaNSchottky}$ diode for different temperatures.

Fig .2 Temperature-dependent of the Schottky barrier height and the ideality factor.

Fig.3 The Schottkybarrier height as a function of the ideality factor.

Fig.4 The leakage current at a bias voltage $(-10 \mathrm{~V})$ as a function of temperature for (Mo/Au)/AlGaN/GaN/Si SBD.

Fig.5 d(V)/dLnI versus current plots for different temperatures.

Fig.6 Temperature-dependent of $\mathrm{R}_{\mathrm{s}}$ for the SBD.

Fig.7 Plots of H(I) vs I for SBD for different temperatures.

Fig.8 The zero-bias apparent barrier height $\Phi_{\mathrm{B} 0(\mathrm{I}-\mathrm{V})}$ versus $(\mathrm{q} / 2 \mathrm{kT})$.

Fig.9 The ideality factor $1 / \boldsymbol{\eta}_{\text {app }}-1$ versus $q / 2 k T$ for the SBD.

Fig.10 Modified Richardson plot $\operatorname{Ln} \frac{\mathrm{I}_{0}}{\mathrm{~T}^{2}}-\frac{\mathrm{q}^{2} \sigma_{0}^{2}}{2 \mathrm{~K}^{2} \mathrm{~T}^{2}}$ versus $\frac{1}{\mathrm{~K} \mathrm{~T}}$ for the

$(\mathrm{Mo} / \mathrm{Au}) / \mathrm{AlGaN} / \mathrm{GaN} / \mathrm{Si}$ Schottky diode according to the double-Gaussian model.

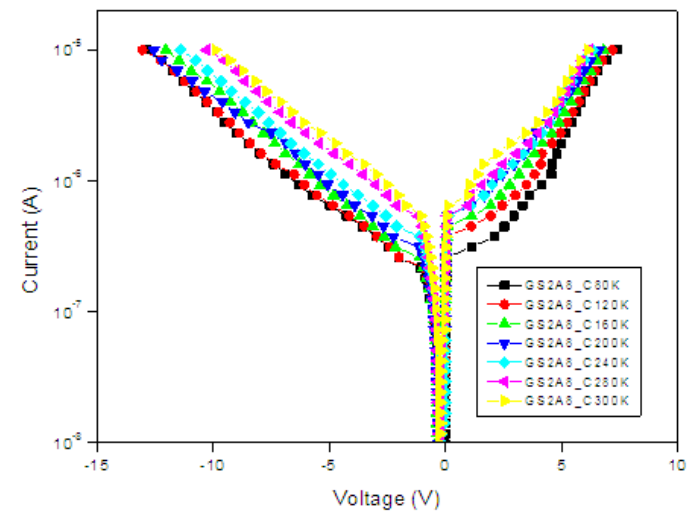

Fig.1

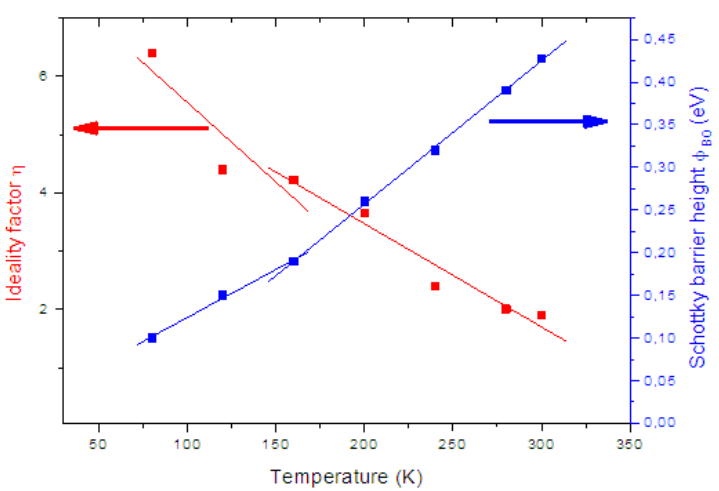

Fig.2 


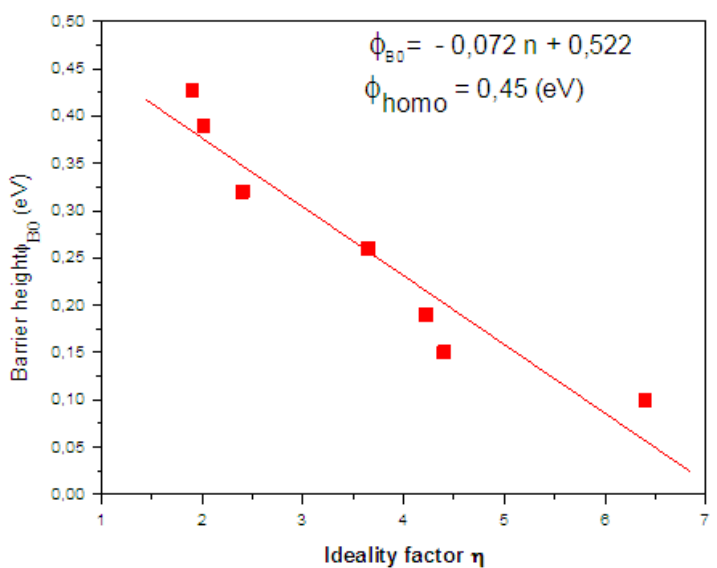

Fig.3

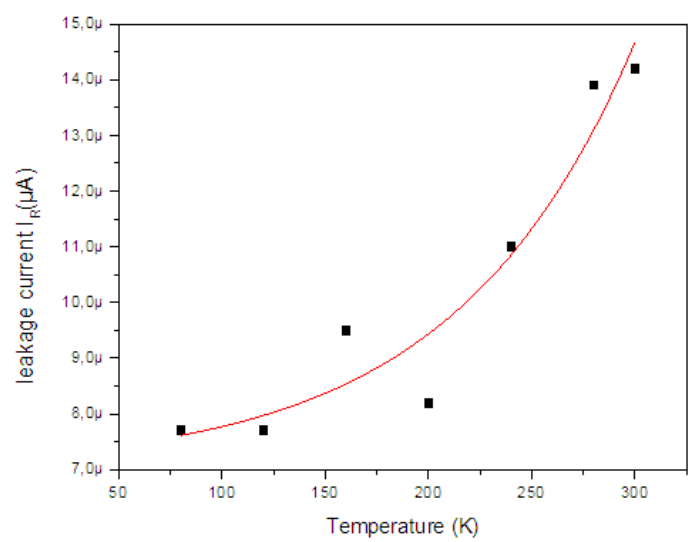

Fig.4

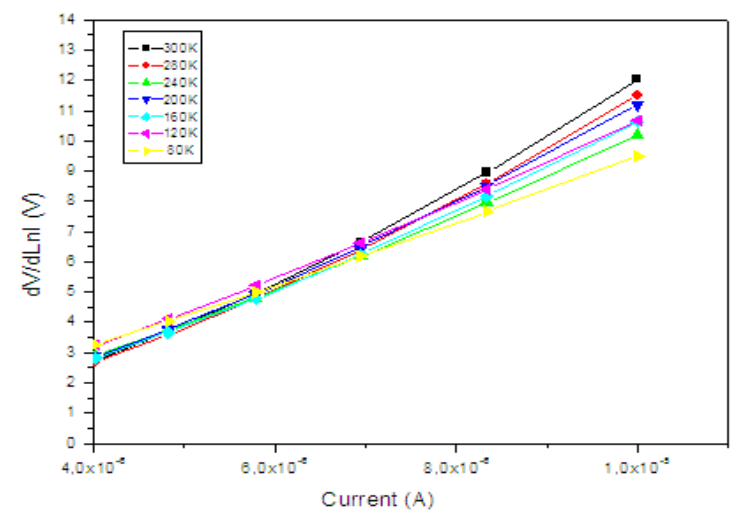

Fig.5

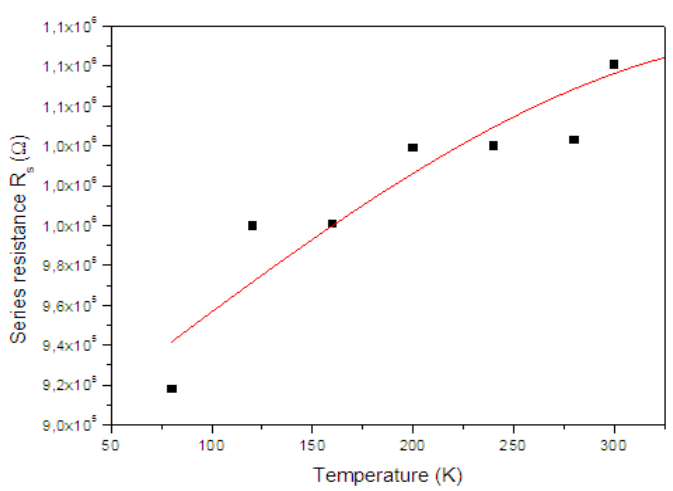

Fig.6 


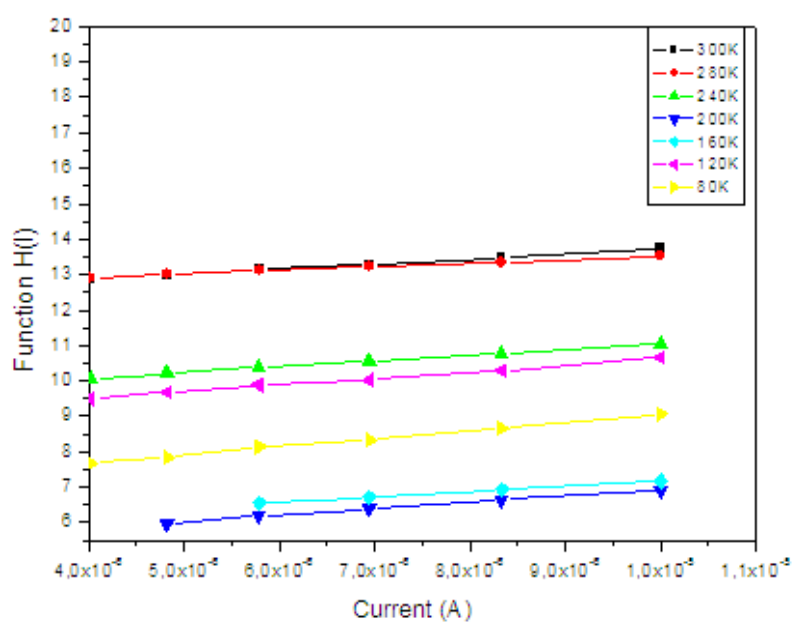

Fig.7

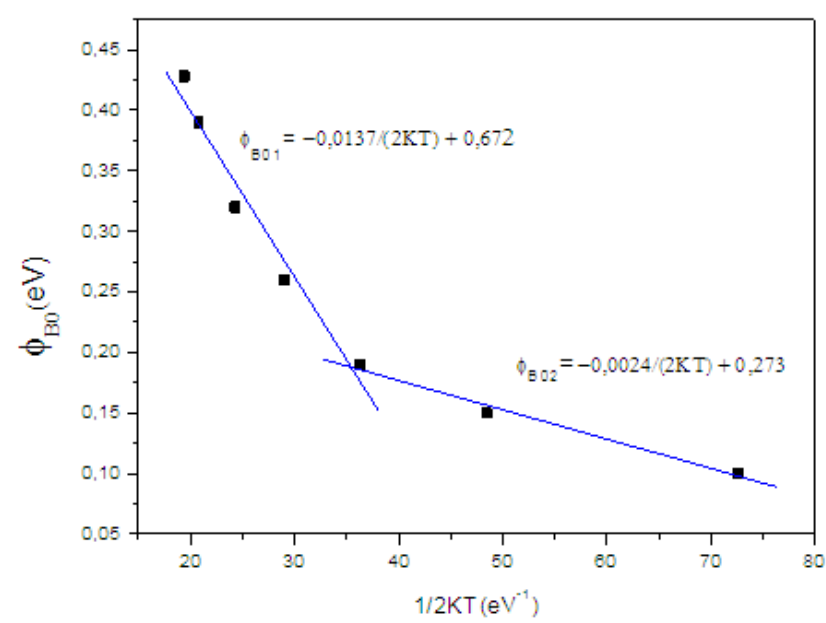

Fig.8

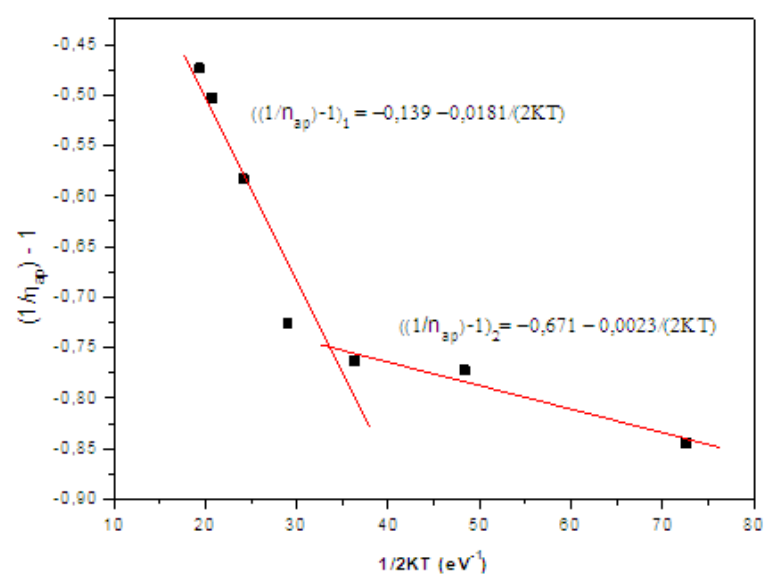

Fig.9 


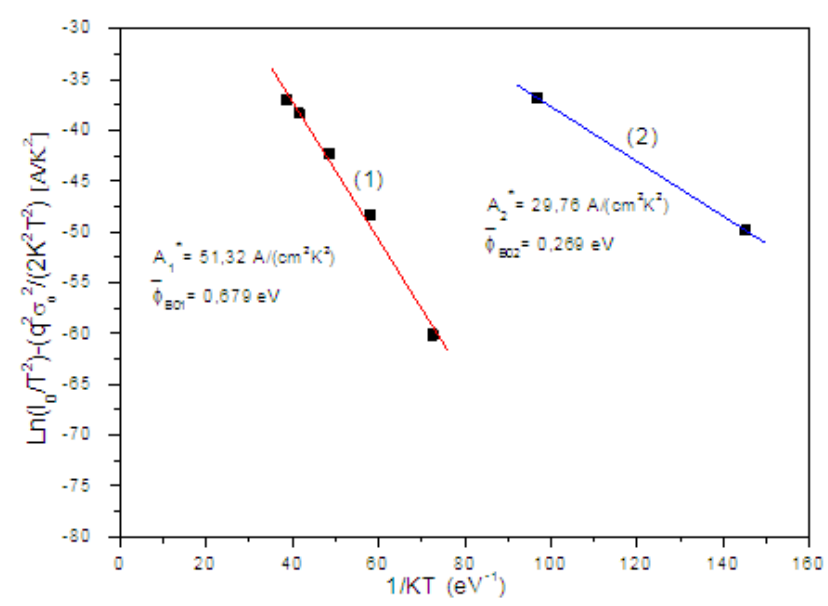

Fig.10

Table caption

Table.1 Values of the Schottkybarrier height of $(\mathrm{Mo} / \mathrm{Au}) / \mathrm{Al}_{0.26} \mathrm{Ga}_{0.74} \mathrm{~N} / \mathrm{GaN} \mathrm{SBD}$ as evaluated fromI-V, Cheung and Norde'smethods.

\begin{tabular}{llccl}
\hline \hline Temperature & $\Phi_{\text {B0(I-V) }}(\mathrm{eV})$ & \multicolumn{2}{c}{$\Phi_{\text {Bo(Cheung) }}(\mathrm{eV})$} & $\Phi_{\text {Bo( (Werner) }}(\mathrm{eV})$ \\
\hline \hline 300 & 0.42 & 0.51 & 0.672 & \\
280 & 0.39 & 0.48 & & 0.672 \\
240 & 0.32 & 0.46 & 0.672 & \\
200 & 0.26 & 0.26 & & 0.672 \\
160 & 0.19 & 0.23 & 0.273 & \\
120 & 0.15 & 0.15 & & 0.273 \\
80 & 0.10 & 0.13 & & 0.273 \\
\hline \hline
\end{tabular}

